\title{
Gabapentinoids in penitentiaries: An abuse and addiction research
}

\author{
İlker İlhanll, ${ }^{1}$ Necip Güder, ${ }^{2}$ Murat Gül ${ }^{3}$ \\ ${ }^{1}$ Department of Physical Medicine and Rehabilitation, School of Medicine, Giresun University, Giresun, Turkey \\ ${ }^{2}$ Department of Physical Medicine and Rehabilitation, Giresun Physical Therapy and Rehabilitation Hospital, Giresun, Turkey \\ ${ }^{3}$ Department of Statistics, Giresun University Faculty of Science, Giresun, Turkey \\ Received: June 2016 Accepted: November 2016
}

\begin{abstract}
Objectives: This study aims to examine the abuse and addiction of gabapentinoids in penal institutions.

Patients and methods: Between September 2014 and November 2014, a total of 1,639 participants were administered an electronic questionnaire investigating the drug use and addiction. The questionnaire was requested to be asked and filled by the officers in charge for all voluntary convicts and prisoners in all penitentiaries throughout Turkey.

Results: The rate of answering the questions varied between $20.5 \%$ and $100 \%$. It was found that $2 \%$ of the participants used pregabalin and gabapentin simultaneously, while $25.2 \%$ of them used multiple drugs. The usage rate of pregabalin and gabapentin was higher in some penitentiaries, compared to the normal population. There was a significant positive correlation between the use of gabapentinoids and multiple drugs and alcohol and drug addiction, various withdrawal symptoms, the number of going to the infirmary, and the number of referral to the hospital $(\mathrm{p}<0.05)$.

Conclusion: Although gabapentinoids seem to be used in the treatment of addiction, and are proved effective treatment agents. With a definite diagnosis, appropriate follow-up, and timely completion of the treatment, it is necessary to strictly control their use due to the probability of abuse and addiction.
\end{abstract}

Keywords: Abuse; addiction; gabapentin; gabapentinoid; pregabalin.

Gabapentinoids (gabapentin and pregabalin) are antiepileptic drugs used in the treatment of primary focal and secondary generalized epilepsy, the former of which makes $\mathrm{N}$-type calcium channel modulation and is eliminated from the body $100 \%$ by kidneys and the latter of which acts by binding to $\alpha 2 \delta$ subunit of the voltage-gated calcium channel and is eliminated from the body $95 \%$ by kidneys. Pregabalin has a six times stronger binding affinity to this subunit of the calcium channels than gabapentin. ${ }^{[1-5]}$ As a result of calcium release from the nerve endings, it reduces the release of various neurotransmitters such as glutamate, norepinephrine, and substance $\mathrm{P}^{[6-8]}$ Pregabalin does not act through the gamma-aminobutyric acid (GABA) receptors, and does not change the GABA uptake and degradation. ${ }^{[9,10]}$ Neither drug binds to the plasma proteins, and interacts with liver enzymes and other drugs. ${ }^{[1]}$ The well-known side effects of gabapentin are somnolence, dizziness, ataxia, fatigue, nystagmus, weight gain, and behavior disorders in children and side effects of pregabalin are mild temporary elevations in the liver enzymes, somnolence, fatigue, dizziness, and weight gain. ${ }^{[1]}$

Pregabalin is primarily used in the treatment of epilepsy and neuropathic pain, and also in the treatment of addiction of alcohol and benzodiazepine. ${ }^{[12]}$ Similarly, based on the central mechanisms in the etiopathogenesis of fibromyalgia syndrome, antiepileptics are considered to be tested in the treatment. Pregabalin is the first agent to be deemed suitable for the treatment of fibromyalgia syndrome by the United States Food and Drug Administration. ${ }^{[13]}$ In regard to the use of gabapentin in fibromyalgia, a randomized placebo-controlled study is available in the literature. ${ }^{[14]}$

According to the data obtained by examining the commercial records (provided by the drug companies 
in Turkey), the use and institutional costs of these drugs have been gradually increasing worldwide (Figure 1). While the quantity of gabapentin sold in Turkey in 2011 was 3,725,927 boxes, this number increased up to $4,621,100$ boxes in 2014 . The quantity of pregabalin sold was 896,744 boxes in 2011, while this number was $2,997,515$ boxes in 2014 . The money spent for pregabalin was 13,130,220 US Dollars in 2011, while it was 23,433,991 US Dollars in 2014.

Gabapentin has been shown to be associated with euphoria as a side effect in 1 to $10 \%$ of patients. ${ }^{[15]}$ Also, there are case reports of probable addiction of gabapentinoids. ${ }^{[16,17]}$ Although they are considered as effective drugs, they are also regarded as the drugs potentially developing clinical abuse. ${ }^{[15-18]}$

In the present study, we aimed to examine the abuse and addiction of gabapentinoids which have been becoming more widespread around the world, in penal institutions where the probability of addiction is estimated to be higher, in terms of improving the health and training of the convicts and prisoners in the penal institutions, and developing the drug policies of the institutions. ${ }^{[19]}$

\section{PATIENTS AND METHODS}

Upon receiving the official and ethical approval of Turkish Republic Ministry of Justice General Directorate of Penitentiary and Detention Institutions, dated 25/08/2014 and numbered 57292265-204.06.03-1445/134224, a questionnaire investigating the drug use and addiction was prepared in the electronic environment, and it was requested to be asked and filled by officers in charge for all the convicts and prisoners who accepted to participate in the study and signed the written consent in all penitentiaries throughout Turkey. The study was conducted in accordance with the principles of the Declaration of Helsinki. By conforming to the privacy, it was ensured that the questionnaires were collected in a pool in electronic environment which can only be reached by the researchers. The data obtained was subjected to statistical analysis by an expert statistician. The results of this project were allowed to be published with the approval of Turkish Republic Ministry of Justice, dated 24/12/2015 and numbered 57292265204.06.03-E.2013/188853.

\section{Statistical analysis}

Statistical analysis was performed using the PASW version 17.0 statistical software (SPSS Inc., Chicago, IL,
USA). Descriptive statistics were expressed in median (min-max) values and number and percentage. The chi-square and Cramer's $\mathrm{V}$ tests were used to assess the correlations. A $p$ value of $<0.05$ was considered statistically significant.

\section{RESULTS}

A total of 1,639 participants attended to the questionnaire study. The response rate of the participants differed for each question, as it was based on volunteering (range, 20.5 to $100 \%$; Table 1). According to the numbers of the individuals using pregabalin and gabapentin in each penal institution, it was found that the total number of the individuals using pregabalin and gabapentin was above the number of the participants in some institutions (e.g., Adana/Kozan and Nigde E type), which was due to the fact that some of the participants used pregabalin and gabapentin simultaneously (Table 2).
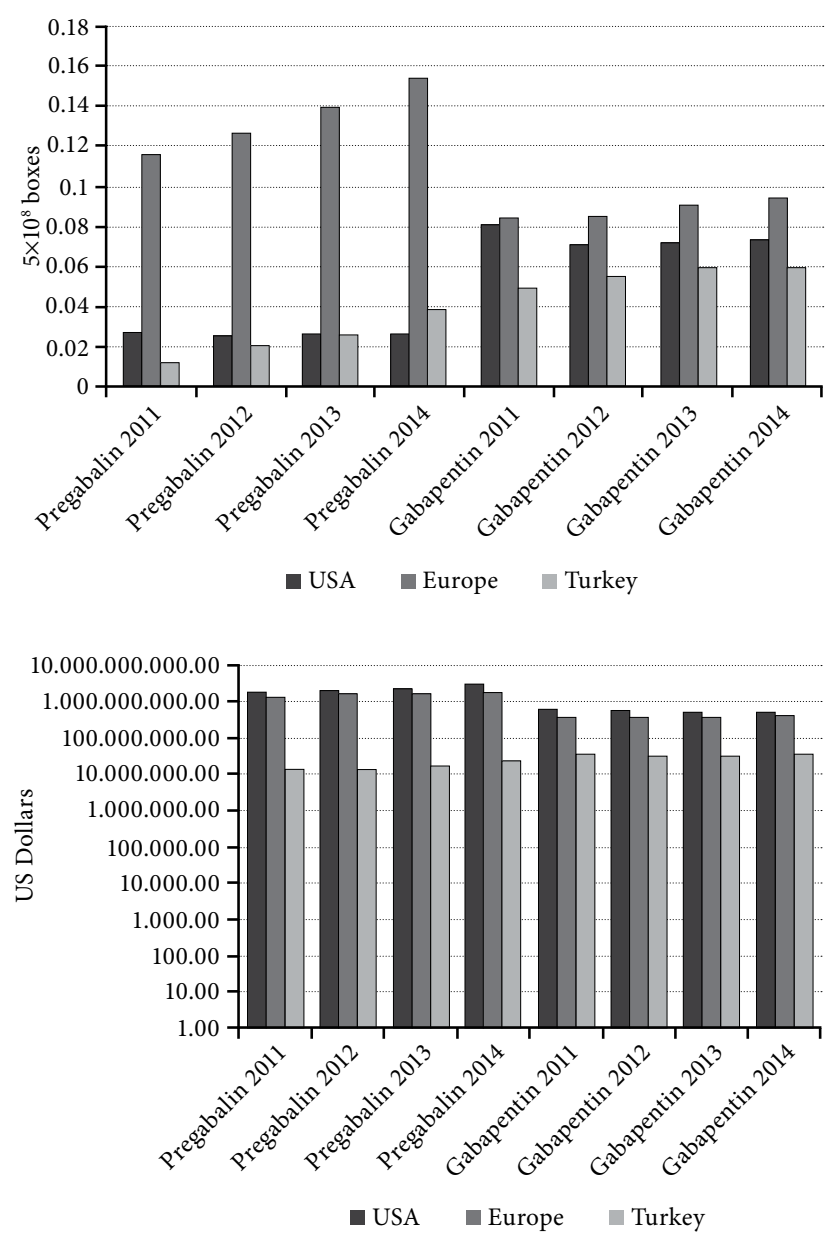

Figure 1. The population ratio of the sold pillbox numbers and institutional costs of pregabalin and gabapentin in US Dollars in the markets of USA, Europe and Turkey in 2011, 2012, 2013 and 2014. 
The rate of the individuals participated in the questionnaire and using gabapentinoids are shown in Table 3.

A total of 302 (23.1\%) participants were using pregabalin. Ninety seven (27.6\%) of the participants had drug reports provided by the hospitals. The question asking the usage frequency of pregabalin was answered as once a day by $25.8 \%$, twice a day by $59.8 \%$, three times a day by $14.0 \%$, and four times a day by $0.3 \%$. The median value of the duration of pregabalin use was five (range, 2 to 13) months. The percent of the individuals using pregabalin for $\geq 6$ months was $48.5 \%$.

Table 1. Number and percent of the participants to each question $(n=1,639)$

\begin{tabular}{|c|c|c|}
\hline Question & Number of the participants & Percent of the participants (\%) \\
\hline Usage of pregabalin? & 1567 & 95.5 \\
\hline Drug report for pregabalin? & 352 & 21.5 \\
\hline Usage period for pregabalin (month) & 336 & 20.5 \\
\hline Frequency of pregabalin usage & 356 & 21.7 \\
\hline Dose of pregabalin & 356 & 21.7 \\
\hline Pregabalin started before imprisonment? & 366 & 22.3 \\
\hline Usage of gabapentin? & 1559 & 95.1 \\
\hline Drug report for gabapentin? & 414 & 25.2 \\
\hline Usage period for gabapentin (months) & 371 & 22.6 \\
\hline Frequency of gabapentin usage & 422 & 25.7 \\
\hline Dose of gabapentin & 423 & 25.8 \\
\hline Gabapentin started before imprisonment? & 428 & 26.1 \\
\hline Usage of antidepressant, antipsychotic or other antiepileptic drugs? & 1621 & 98.9 \\
\hline Drug report for other drugs? & 1078 & 65.8 \\
\hline Usage period for other drugs (months) & 1003 & 61.2 \\
\hline Frequency of usage of other drugs & 1071 & 65.3 \\
\hline Doses of other drugs & 1061 & 64.7 \\
\hline Other drugs started before imprisonment? & 1092 & 66.6 \\
\hline Diagnosis & 1639 & 100 \\
\hline Name of the drugs & 1639 & 100 \\
\hline Multiple drug usage & 1634 & 99.6 \\
\hline In which step of health institution the drugs were started? & 1498 & 91.3 \\
\hline Alcohol addiction & 1411 & 86 \\
\hline Dope addiction & 1446 & 88.2 \\
\hline Going to the infirmary (last 1 year) & 1233 & 75.2 \\
\hline Going to the infirmary (last 6 months) & 1639 & 100 \\
\hline Going to the infirmary (last 3 months) & 1080 & 65.9 \\
\hline Referring to the hospital (last 1 year) & 1171 & 71.4 \\
\hline Referring to the hospital (last 6 months) & 950 & 57.9 \\
\hline Referring to the hospital (last 3 months) & 946 & 57.7 \\
\hline Duration of imprisonment (intervals of months or years) & 1377 & 84 \\
\hline Tend to engage in violence against others? & 1559 & 95.1 \\
\hline Tend to engage in violence against the self? & 1555 & 94.8 \\
\hline \multicolumn{3}{|l|}{ Withdrawal symptoms occurring when the drug is not used } \\
\hline Sweating & 985 & 60.1 \\
\hline Shivering & 1021 & 62.3 \\
\hline Having fever & 932 & 56.8 \\
\hline Stomachache & 894 & 54.5 \\
\hline Nausea & 900 & 54.9 \\
\hline Vomiting & 880 & 53.7 \\
\hline Palpitation & 960 & 58.5 \\
\hline Hallucination & 954 & 58.2 \\
\hline Headache & 1063 & 64.8 \\
\hline Dizziness & 952 & 58 \\
\hline Nervousness & 1294 & 78.9 \\
\hline Sleeplessness & 1318 & 80.4 \\
\hline Nightmare & 947 & 57.7 \\
\hline Epileptic seizure & 883 & 53.8 \\
\hline Xerostomia & 958 & 58.4 \\
\hline Restlessness & 1368 & 83.4 \\
\hline
\end{tabular}


Table 2. Penal institutions, number of participants and number of participants using pregabalin or gabapentin $(n=1,639)$

\begin{tabular}{|c|c|c|c|c|c|c|c|c|c|c|c|}
\hline Institution & NP & $\mathrm{P}$ & G & Institution & NP & $\mathrm{P}$ & G & Institution & NP & $\mathrm{P}$ & G \\
\hline Null & 6 & 1 & 0 & Diyarbakır & 2 & 1 & 0 & $\begin{array}{l}\text { Kocaeli } \\
\text { F type }\end{array}$ & 30 & 2 & 2 \\
\hline $\begin{array}{l}\text { Adana } \\
\text { F type }\end{array}$ & 6 & 0 & 2 & Erzurum & 18 & 3 & 2 & Konya & 13 & 6 & 3 \\
\hline $\begin{array}{l}\text { Adana } \\
\text { Karataş }\end{array}$ & 9 & 0 & 1 & $\begin{array}{l}\text { Erzurum } \\
\text { Oltu }\end{array}$ & 48 & 4 & 7 & $\begin{array}{l}\text { Konya } \\
\text { Beyșehir }\end{array}$ & 5 & 1 & 2 \\
\hline $\begin{array}{l}\text { Adana } \\
\text { Kozan }\end{array}$ & 5 & 4 & 4 & $\begin{array}{l}\text { Eskişehir } \\
\text { Open }\end{array}$ & 15 & 4 & 2 & $\begin{array}{l}\text { Konya } \\
\text { Seydișehir }\end{array}$ & 3 & 0 & 1 \\
\hline Adiyaman & 2 & 0 & 2 & Gaziantep & 5 & 0 & 1 & Manisa & 45 & 5 & 12 \\
\hline Afyon & 29 & 2 & 18 & Giresun & 33 & 6 & 27 & $\begin{array}{l}\text { Manisa } \\
\text { Akhisar }\end{array}$ & 4 & 0 & 1 \\
\hline $\begin{array}{l}\text { Afyon } \\
\text { Sandiklı }\end{array}$ & 7 & 0 & 5 & $\begin{array}{l}\text { Hatay } \\
\text { Closed }\end{array}$ & 1 & 0 & 0 & $\begin{array}{l}\text { Manisa } \\
\text { Alaşehir }\end{array}$ & 1 & 0 & 0 \\
\hline Ağrı & 14 & 0 & 3 & $\begin{array}{l}\text { Isparta } \\
\text { Yalvaç }\end{array}$ & 3 & 0 & 0 & Mersin & 149 & 2 & 6 \\
\hline Ankara & 120 & 46 & 9 & İstanbul & 37 & 8 & 10 & Muğla & 60 & 39 & 6 \\
\hline $\begin{array}{l}\text { Ankara } \\
\text { Ayas }\end{array}$ & 5 & 2 & 2 & $\begin{array}{l}\text { İstanbul } \\
\text { L type }\end{array}$ & 14 & 1 & 2 & Nevşehir & 7 & 0 & 7 \\
\hline $\begin{array}{l}\text { Ankara } \\
\text { Kizılcahamam }\end{array}$ & 11 & 7 & 2 & $\begin{array}{l}\text { İstanbul } \\
\text { Silivri }\end{array}$ & 19 & 6 & 6 & $\begin{array}{l}\text { Niğde } \\
\text { Open }\end{array}$ & 10 & 2 & 4 \\
\hline Antalya & 26 & 3 & 2 & İzmir & 24 & 3 & 3 & $\begin{array}{l}\text { Niğde } \\
\text { E type }\end{array}$ & 11 & 1 & 11 \\
\hline Ardahan & 4 & 0 & 0 & $\begin{array}{l}\text { İzmir } \\
\text { Aliağa }\end{array}$ & 4 & 1 & 2 & Osmaniye & 6 & 0 & 2 \\
\hline Aydın & 5 & 0 & 2 & $\begin{array}{l}\text { İzmir } \\
\text { Bergama }\end{array}$ & 50 & 18 & 4 & Rize & 13 & 1 & 2 \\
\hline $\begin{array}{l}\text { Aydın } \\
\text { Söke }\end{array}$ & 1 & 0 & 0 & $\begin{array}{l}\text { İzmir } \\
\text { Ödemiş }\end{array}$ & 11 & 0 & 6 & Samsun & 58 & 11 & 8 \\
\hline Balıkesir & 22 & 8 & 8 & $\begin{array}{l}\text { İzmir } \\
\text { T type }\end{array}$ & 7 & 7 & 0 & $\begin{array}{l}\text { Samsun } \\
\text { Bafra }\end{array}$ & 47 & 12 & 12 \\
\hline $\begin{array}{l}\text { Balıkesir } \\
\text { Bandırma }\end{array}$ & 12 & 0 & 5 & Kahramaraş & 44 & 3 & 24 & $\begin{array}{l}\text { Samsun } \\
\text { Çarşamba }\end{array}$ & 6 & 0 & 0 \\
\hline $\begin{array}{l}\text { Balıkesir } \\
\text { L type }\end{array}$ & 1 & 1 & 0 & Karabük & 15 & 6 & 1 & Sinop & 21 & 3 & 3 \\
\hline Batman & 11 & 0 & 4 & Karaman & 5 & 0 & 5 & $\begin{array}{l}\text { Sinop } \\
\text { Boyabat }\end{array}$ & 4 & 1 & 2 \\
\hline Bitlis & 25 & 2 & 9 & $\begin{array}{l}\text { Karaman } \\
\text { Ermenek }\end{array}$ & 6 & 0 & 6 & Şanlıurfa & 15 & 6 & 1 \\
\hline Bolu & 53 & 15 & 8 & Kastamonu & 18 & 6 & 15 & Şırnak & 61 & 5 & 13 \\
\hline $\begin{array}{l}\text { Bolu } \\
\text { F type }\end{array}$ & 27 & 9 & 6 & $\begin{array}{l}\text { Kastamonu } \\
\text { Daday }\end{array}$ & 4 & 0 & 3 & Tekirdağ & 8 & 0 & 1 \\
\hline Burdur & 23 & 6 & 12 & Kayseri & 4 & 0 & 2 & $\begin{array}{l}\text { Tekirdağ } \\
\text { Open }\end{array}$ & 1 & 0 & 0 \\
\hline Bursa & 4 & 1 & 0 & Kirıkkale & 46 & 9 & 16 & $\begin{array}{l}\text { Tekirdağ } \\
\text { F type }\end{array}$ & 16 & 0 & 8 \\
\hline $\begin{array}{l}\text { Bursa } \\
\text { H type }\end{array}$ & 11 & 3 & 1 & $\begin{array}{l}\text { Kirıkkale } \\
\text { Sulakyurt }\end{array}$ & 6 & 4 & 2 & Tokat & 3 & 0 & 3 \\
\hline Çorum & 12 & 4 & 4 & Kırklareli & 8 & 5 & 1 & $\begin{array}{l}\text { Tokat } \\
\text { Zile }\end{array}$ & 22 & 0 & 3 \\
\hline $\begin{array}{l}\text { Çorum } \\
\text { Sungurlu } \\
\text { Çorum }\end{array}$ & 5 & 4 & 1 & Kırşehir & 97 & 50 & 41 & Tunceli & 6 & 0 & 6 \\
\hline Sungurlu & 5 & 4 & 1 & Kırşehir & 97 & 50 & 41 & Tunceli & 6 & 0 & 6 \\
\hline Denizli & 4 & 0 & 4 & Kocaeli & 5 & 2 & 3 & Yalova & 5 & 0 & 0 \\
\hline
\end{tabular}


Table 3. Percent of the individuals participated in the questionnaire, and percent of the individuals using gabapentinoids

\begin{tabular}{|c|c|c|c|c|c|c|c|c|c|c|c|}
\hline City & A & B & $\mathrm{C}$ & $\mathrm{D}$ & $\mathrm{E}$ & City & A & B & $\mathrm{C}$ & $\mathrm{D}$ & $\mathrm{E}$ \\
\hline Adana & 20 & 4,457 & 0.45 & 11 & 0.25 & Kahramanmaraş & 44 & 1966 & 2.24 & 27 & 1.37 \\
\hline Adiyaman & 2 & 1,427 & 0.14 & 2 & 0.14 & Karabük & 15 & 1121 & 1.34 & 7 & 0.62 \\
\hline Afyon & 36 & 2,269 & 1.59 & 25 & 1.1 & Karaman & 11 & 1099 & 1 & 11 & 1 \\
\hline$A \breve{g} r 1$ & 14 & 531 & 2.64 & 3 & 0.56 & Kastamonu & 22 & 1159 & 1.9 & 22 & 1.9 \\
\hline Ankara & 136 & 6,661 & 2.04 & 68 & 1.02 & Kayseri & 4 & 1710 & 0.23 & 2 & 0.12 \\
\hline Antalya & 26 & 3,817 & 0.68 & 5 & 0.13 & Kirıkkale & 52 & 607 & 8.57 & 31 & 5.11 \\
\hline Ardahan & 4 & 70 & 5.71 & 0 & 0 & Kırklareli & 8 & 1694 & 0.47 & 6 & 0.35 \\
\hline Aydin & 6 & 2,754 & 0.22 & 2 & 0.07 & Kırşehir & 97 & 1257 & 7.7 & 91 & 7.24 \\
\hline Balıkesir & 35 & 4,823 & 0.73 & 22 & 0.46 & Kocaeli & 35 & 3595 & 0.97 & 9 & 0.25 \\
\hline Batman & 11 & 453 & 2.43 & 4 & 0.88 & Konya & 21 & 2380 & 0.88 & 13 & 0.55 \\
\hline Bitlis & 25 & 626 & 4 & 11 & 1.76 & Manisa & 50 & 3148 & 1.59 & 18 & 0.57 \\
\hline Bolu & 80 & 1,657 & 4.83 & 38 & 2.3 & Mersin & 149 & 3321 & 4.49 & 8 & 0.24 \\
\hline Burdur & 23 & 1,162 & 1.98 & 18 & 1.55 & Muğla & 60 & 2102 & 2.85 & 45 & 2.14 \\
\hline Bursa & 15 & 3,598 & 0.42 & 5 & 0.14 & Nevşehir & 7 & 667 & 1.05 & 7 & 1.05 \\
\hline Çorum & 17 & 1,903 & 0.9 & 13 & 0.68 & Niğde & 21 & 1269 & 1.65 & 18 & 1.42 \\
\hline Denizli & 4 & 2,481 & 0.16 & 4 & 0.16 & Osmaniye & 6 & 2159 & 0.28 & 2 & 0.09 \\
\hline Diyarbakır & 2 & 2,580 & 0.08 & 1 & 0.04 & Rize & 13 & 983 & 1.32 & 3 & 0.31 \\
\hline Erzurum & 66 & 2,131 & 3.1 & 16 & 0.75 & Samsun & 111 & 2492 & 4.45 & 43 & 1.73 \\
\hline Eskişehir & 15 & 1,967 & 0.76 & 6 & 0.31 & Sinop & 25 & 852 & 2.93 & 9 & 1.06 \\
\hline Gaziantep & 5 & 3,409 & 0.15 & 1 & 0.03 & Şanlıurfa & 15 & 1722 & 0.87 & 7 & 0.41 \\
\hline Giresun & 33 & 856 & 3.86 & 33 & 3.86 & Şırnak & 61 & 1193 & 5.11 & 18 & 1.51 \\
\hline Hatay & 1 & 2,551 & 0.04 & 0 & 0 & Tekirdağ & 25 & 3156 & 0.8 & 9 & 0.29 \\
\hline Isparta & 3 & 1,219 & 0.25 & 0 & 0 & Tokat & 25 & 1673 & 1.5 & 6 & 0.36 \\
\hline İstanbul & 70 & 19,338 & 0.36 & 33 & 0.17 & Tunceli & 6 & 51 & 11.76 & 6 & 11.76 \\
\hline İzmir & 96 & 10,051 & 0.96 & 42 & 0.42 & Yalova & 5 & 51 & 9.8 & 0 & 0 \\
\hline
\end{tabular}

A: Total number of the prisoners and convicts participated in the questionnaire on the basis of city; B: Total number of the prisoners and convicts on the basis of city; C: Percent of the individuals participated in the questionnaire; D: Number of the individuals using gabapentinoids; E: Percent of the individuals using gabapentinoids.

The question about when pregabalin was started was answered as after imprisonment by $59 \%$ of the participants. The question asking the daily pregabalin dose was answered as below: $50 \mathrm{mg}$ by $1.7 \%, 50-150 \mathrm{mg}$ by $20.2 \%, 150-300 \mathrm{mg}$ by $34.3 \%, 300-600 \mathrm{mg}$ by $31.2 \%$, $600-1,200 \mathrm{mg}$ by $10.4 \%, 1,200-1,800 \mathrm{mg}$ by $1.7 \%$, and more than $1,800 \mathrm{mg}$ by $0.6 \%$.

A total of $425(27.3 \%)$ participants were using gabapentin. A hundred and seventy eight (43\%) of them had a drug report. A total of $14.9 \%$ of the participants used gabapentin once a day, $31.8 \%$ twice a day, $49.5 \%$ three times a day, 3.8\% four times a day. According to the total daily dose of gabapentin, those using it below $300 \mathrm{mg}$ were $6.6 \%, 300-600 \mathrm{mg}$ were $12.8 \%$, $600-1,200 \mathrm{mg}$ were $32.9 \%, 1,200-1,800 \mathrm{mg}$ were $17.3 \%$ and more than $1,800 \mathrm{mg}$ were $30.5 \%$. The question about when gabapentin was started was answered as after imprisonment by $54.4 \%$ of the participants.

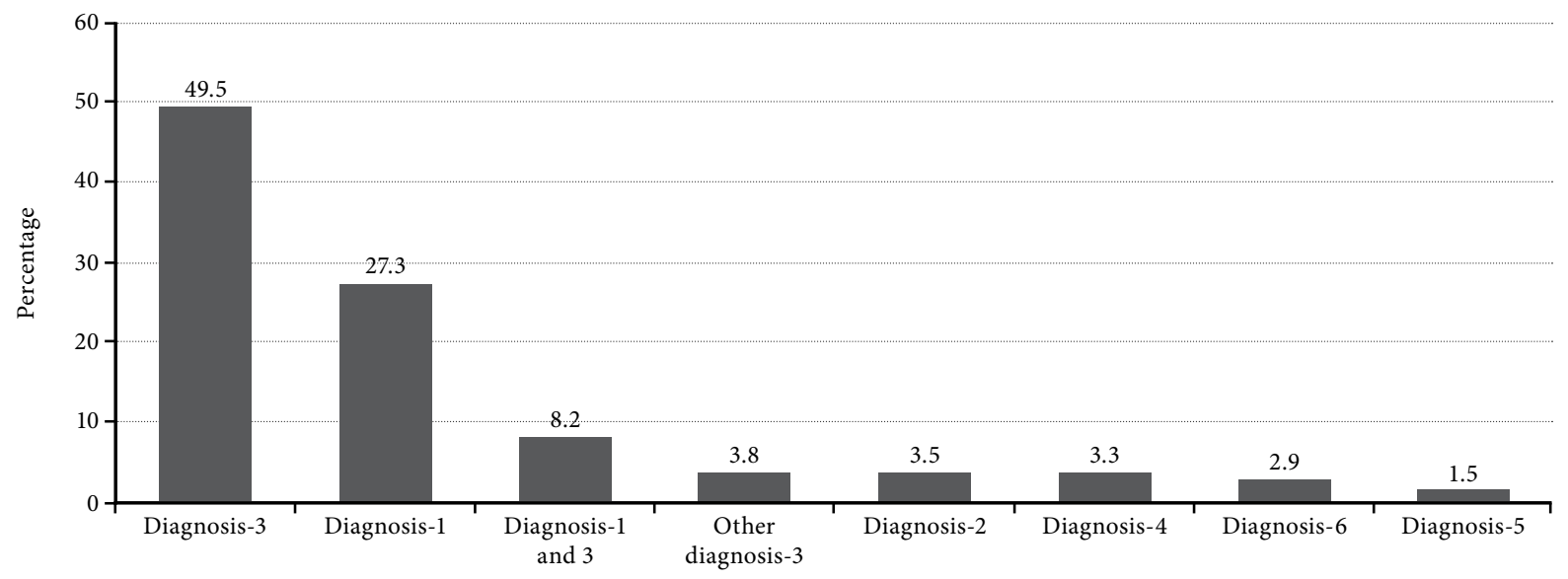

Figure 2. Percents of the diagnosis of the participants $(n=1,639)$. Diagnosis-1: Neuropathic pain; Diagnosis-2: Chronic pain; Diagnosis-3: Depression; Diagnosis-4: Psychosis; Diagnosis-5: Fibromyalgia syndrome; Diagnosis-6: Epilepsy; Other diagnosis: Allergy etc. 
The median value of the duration of gabapentin use was 10 (range, 4 to 20) months. The percent of the individuals using gabapentin for $\geq 6$ months was $64.7 \%$. It was shown that 36 participants (2\%) were using both pregabalin and gabapentin simultaneously.

A total of 1,067 participants (65.8\%) were using an antidepressant, antipsychotic, or other antiepileptic drugs (other than pregabalin and gabapentin). A total of $14.7 \%$ of the participants had a drug report. The question asking the usage frequency of these drugs was answered as once a day by $71 \%$, twice by $25 \%$, three times by $3.5 \%$ and four times by $0.4 \%$. While $43.1 \%$ of the participants were using the drugs at a dose $\leq 50 \mathrm{mg}$, $56.9 \%$ of them were using them at a dose above $50 \mathrm{mg}$. Also, $52.9 \%$ of the participants started these drugs after imprisonment. The rate of those who used these drugs for $\geq 6$ months was $56.5 \%$ and median value of the duration of the drug use was eight (range, 3 to 20) months.

The rates of the diagnosis are shown in Figure 2. The percent of gabapentinoid users was $33.7 \%$, antidepressant users was $20.4 \%$, antipsychotic users was $15.9 \%$, gabapentinoid + antipsychotic users was $8.1 \%$, gabapentinoid + antidepressant users was $6.5 \%$, gabapentinoid + antidepressant + antipsychotic users was $2 \%$. However, $25.2 \%$ of the participants gave the answer 'Yes' to the question of multiple drug use.

While the percent of alcohol use was $58.2 \%$ (415 social drinkers and 407 addicted), the percent of those who were addicted was $28.8 \%$. Also, $50.9 \%$ of the participants used dope (164 social drinkers and 573 addicted), while $39.6 \%$ were addicted. In addition, $27.6 \%$ of the participants tended to engage in violence against others, while $28.9 \%$ of them tended to engage in violence against the self.

The rates of going to the infirmary and referring to the hospital numbers of participants are given in Table 4.

The highest rates among the withdrawal symptoms were seen in restlessness (75.7\%), sleeplessness (73.5\%), and nervousness (73.0\%). Other withdrawal symptoms were headache (50.5\%), shivering (42.1\%), sweating (39.1\%), xerostomia (33.4\%), palpitation (31\%), nightmare (28.9\%), having fever (28.4\%), hallucination $(26.4 \%)$, dizziness $(24.9 \%)$, nausea (15.2\%), stomachache (13.1\%), epileptic seizure (11.2\%), and vomiting (9.7\%). Withdrawal symptoms reported by the participants with their individual expressions apart from the questions asked were pain in different regions of the body, thinking of bad things, allergic symptoms and acnes in the body, anti-sociality, hyper-reflection, paresthesia in the feet, burning and itching, contractions and cramping, fainting, biting lips, fatigue, depression, reluctance to work, discouragement and fear, urinary incontinence at night, restless leg syndrome, melancholy, tendency to be asocial, diarrhea, lack of appetite, teeth grinding, self-destruction and giving harm to others, panic

Table 4. Percents of going to the infirmary and referring to the hospital numbers of participants in last three months, six months and one year

\begin{tabular}{|c|c|c|c|}
\hline Number of going to the infirmary & $\begin{array}{c}\text { Last } 3 \text { months }(\mathrm{n}=1,080) \\
(\%)\end{array}$ & $\begin{array}{l}\text { Last } 6 \text { months }(\mathrm{n}=1,639) \\
(\%)\end{array}$ & $\begin{array}{c}\text { Last } 1 \text { year }(\mathrm{n}=1,233) \\
(\%)\end{array}$ \\
\hline 0 & 0 & 36.2 & 0.2 \\
\hline $1-3$ & 32.1 & 11.0 & 14.4 \\
\hline $4-7$ & 42.5 & 14.3 & 13.1 \\
\hline $8-11$ & 16.0 & 17.6 & 13.0 \\
\hline $12-15$ & 5.2 & 9.8 & 15.7 \\
\hline $16-20$ & 3.0 & 5.9 & 13.9 \\
\hline $21-26$ & 1.2 & 4.9 & 29.1 \\
\hline$>26$ & 0 & 0.2 & 0.6 \\
\hline Number of referring to the hospital & $\begin{array}{l}\text { Last } 3 \text { months }(\mathrm{n}=946) \\
(\%)\end{array}$ & $\begin{array}{l}\text { Last } 6 \text { months }(\mathrm{n}=950) \\
(\%)\end{array}$ & $\begin{array}{c}\text { Last } 1 \text { year }(\mathrm{n}=1,171) \\
(\%)\end{array}$ \\
\hline 0 & 0.2 & 0.1 & 0.2 \\
\hline $1-3$ & 67.8 & 46.4 & 31.5 \\
\hline $4-7$ & 23.4 & 31.1 & 31.1 \\
\hline $8-11$ & 5.7 & 12.1 & 17.2 \\
\hline $12-15$ & 2.3 & 5.6 & 8.4 \\
\hline $16-20$ & 0.4 & 3.4 & 4.4 \\
\hline $21-26$ & 0.2 & 1.1 & 6.9 \\
\hline$>26$ & 0 & 0.3 & 0.3 \\
\hline
\end{tabular}


attack, impatience, suicide attempt, skepticism, becoming seduced, obsession, and being cold.

There was a positive correlation between the pregabalin use and alcohol addiction (Cramer's $\mathrm{V}=0.212$ ), dope addiction (Cramer's $\mathrm{V}=0.147$ ), number of going to the infirmary in the last one year (Cramer's $\mathrm{V}=0.241$ ), last six months (Cramer's $\mathrm{V}=0.229$ ) and last three months (Cramer's $\mathrm{V}=0.223$ ) and number of referring to the hospital in the last one year $(r=0.245)$, last six months (Cramer's V=0.258) and last three months (Cramer's V=0.196). While there was no correlation between pregabalin use and tendency to engage in violence against others (Cramer's $\mathrm{V}=0.030$ ), there was positive correlation between pregabalin use and tendency to engage in violence against the self (Cramer's V=0.072). There was a positive correlation between pregabalin use and withdrawal symptoms such as sweating (Cramer's V=0.059), having fever (Cramer's V=0.091), stomachache (Cramer's V=0.076), nausea (Cramer's V=0.107), vomiting (Cramer's $\mathrm{V}=0.101$ ), hallucination (Cramer's $\mathrm{V}=0.058$ ), headache (Cramer's V $=0.066$ ), nervousness (Cramer's V=0.061), sleeplessness (Cramer's $V=0.139)$, nightmare (Cramer's $\mathrm{V}=0.095)$ and restlessness (Cramer's $\mathrm{V}=0.087$ ).

There was a positive correlation between the duration of pregabalin use and alcohol addiction (Cramer's V=0.186), dope addiction (Cramer's $\mathrm{V}=0.166)$, number of going to the infirmary in the last one year (Cramer's $\mathrm{V}=0.268$ ) and last six months (Cramer's V=0.201), number of referring to the hospital in the last three months (Cramer's V=0.273). While there was no correlation between the duration of pregabalin use and tendency to engage in violence against others (Cramer's $\mathrm{V}=0.066$ ), there was a positive correlation between the duration of pregabalin use and tendency to engage in violence against the self (Cramer's V=0.100).

There was a positive correlation between the duration of pregabalin use and withdrawal symptoms such as stomachache (Cramer's $\mathrm{V}=0.183$ ), palpitation (Cramer's V $=0.151$ ), hallucination (Cramer's $V=0.330$ ), dizziness (Cramer's V=0.221), nervousness (Cramer's $\mathrm{V}=0.153$ ), sleeplessness (Cramer's $\mathrm{V}=0.183$ ), epileptic seizure (Cramer's V $=0.258$ ), xerostomia (Cramer's $\mathrm{V}=0.178$ ) and restlessness (Cramer's $\mathrm{V}=0.134$ ).

In addition, there was a positive correlation between the dose of pregabalin and alcohol addiction (Cramer's $\mathrm{V}=0.152$ ), dope addiction (Cramer's $\mathrm{V}=0.132$ ), number of going to the infirmary in the last six months (Cramer's $\mathrm{V}=0.268$ ), number of referring to the hospital in the last six months (Cramer's V=0.245) and last three months
(Cramer's V=0.229). However, there was no correlation between the dose of pregabalin and tendency to engage in violence either against others or the self (Cramer's $\mathrm{V}=0.073$ and Cramer's V $=0.020$, respectively). There was a positive correlation between the dose of pregabalin and withdrawal symptoms such as sweating (Cramer's $\mathrm{V}=0.155$ ), stomachache (Cramer's $\mathrm{V}=0.166$ ), nausea (Cramer's V=0.154), vomiting (Cramer's V=0201), palpitation (Cramer's V $=0.163$ ), hallucination (Cramer's $\mathrm{V}=0.226$ ), dizziness (Cramer's $\mathrm{V}=0.245$ ), sleeplessness (Cramer's V=0.194), nightmare (Cramer's V=0.257), epileptic seizure (Cramer's $\mathrm{V}=0.240$ ), and xerostomia (Cramer's V=0.245).

There was a positive correlation between the usage frequency of pregabalin and alcohol addiction (Cramer's $V=0.147$ ), number of going to the infirmary in the last one year (Cramer's $V=0.209$ ), last six months (Cramer's $V=0.219$ ), and last three months (Cramer's V=0.186), and number of referring to the hospital in the last three months (Cramer's V=0.160). While there was a correlation between the usage frequency of pregabalin and tendency to engage in violence against others (Cramer's $\mathrm{V}=0.120$ ), there was no correlation between the usage frequency of pregabalin and tendency to engage in violence against the self (Cramer's $V=0.006$ ). There was a positive correlation between the usage frequency of pregabalin and withdrawal symptoms such as sweating (Cramer's $\mathrm{V}=0.229$ ), having fever (Cramer's $\mathrm{V}=0.226$ ), nausea (Cramer's V=0.212), vomiting (Cramer's V=0.294), hallucination (Cramer's V=0.236), dizziness (Cramer's $\mathrm{V}=0.215$ ), sleeplessness (Cramer's $\mathrm{V}=0.211$ ), nightmare (Cramer's V=0.231), epileptic seizure (Cramer's $\mathrm{V}=0.224$ ), and xerostomia (Cramer's $\mathrm{V}=0.167$ ).

There was a positive correlation between the gabapentin use and alcohol addiction (Cramer's $\mathrm{V}=0.125$ ), dope addiction (Cramer's $\mathrm{V}=0.135$ ), number of going to the infirmary in the last one year (Cramer's $\mathrm{V}=0.275$ ), last six months (Cramer's $\mathrm{V}=0.260$ ) and last three months (Cramer's $\mathrm{V}=0.251$ ), and number of referring to the hospital in the last one year (Cramer's $\mathrm{V}=0.179$ ). While there was no correlation between gabapentin use and tendency to engage in violence against others (Cramer's $\mathrm{V}=0.025$ ), there was positive correlation between gabapentin use and tendency to engage in violence against the self (Cramer's V=0.046). There was a positive correlation between gabapentin use and withdrawal symptoms such as sweating (Cramer's $\mathrm{V}=0.060$ ), having fever (Cramer's $\mathrm{V}=0.097$ ), palpitation (Cramer's V=0.056), headache (Cramer's V=0.120), nervousness (Cramer's V=0.094), sleeplessness (Cramer's $\mathrm{V}=0.085$ ), and restlessness (Cramer's $\mathrm{V}=0.076$ ). 
There was positive correlation between the duration of gabapentin use and alcohol addiction (Cramer's $\mathrm{V}=0.227$ ), dope addiction (Cramer's $\mathrm{V}=0.239$ ), number of going to the infirmary in the last one year (Cramer's $\mathrm{V}=0.216$ ) and last six months (Cramer's $\mathrm{V}=0.198$ ), and number of referring to the hospital in the last six months (Cramer's V=0.200). There was a positive correlation between the duration of gabapentin use and tendency to engage in violence against others and against the self (Cramer's V $=0.156$ and Cramer's $\mathrm{V}=0.188$, respectively). There was a positive correlation between the duration of gabapentin use and withdrawal symptoms such as palpitation (Cramer's $\mathrm{V}=0.110$ ), hallucination (Cramer's $\mathrm{V}=0.128$ ), dizziness (Cramer's V=0.169), nervousness (Cramer's V=0.149), sleeplessness (Cramer's V $=0.170$ ), xerostomia (Cramer's $\mathrm{V}=0.136$ ), and restlessness (Cramer's $\mathrm{V}=0.117$ ).

On the other hand, there was no correlation between the dose of gabapentin and alcohol addiction, dope addiction, number of going to the infirmary and referring to the hospital, tendency to engage in violence against others or the self $(p>0.05)$. There was a positive correlation between the dose of gabapentin and withdrawal symptoms such as sweating (Cramer's $\mathrm{V}=0.133$ ), vomiting (Cramer's $\mathrm{V}=0.196$ ), palpitation (Cramer's V=0.149), headache (Cramer's V=0.149), and nervousness (Cramer's V=0.125).

There was a positive correlation between the frequency of gabapentin usage and dope addiction (Cramer's $\mathrm{V}=0.120$ ), number of going to the infirmary in the last one year (Cramer's $\mathrm{V}=0.190$ ) and last six months (Cramer's $\mathrm{V}=0.239$ ). There was a positive correlation between the frequency of gabapentin usage and tendency to engage in violence against others and against the self (Cramer's V $=0.129$ and Cramer's V $=0.184$, respectively). There was a positive correlation between the frequency of gabapentin usage and withdrawal symptom of sleeplessness (Cramer's V $=0.120$ ).

There was a positive correlation between the use of other drugs comprising antidepressant, antipsychotic, and antiepileptics (other than gabapentinoids) and alcohol addiction (Cramer's $\mathrm{V}=0.136$ ), dope addiction (Cramer's V=0.084), number of going to the infirmary in the last one year (Cramer's $V=0.286$ ), last six months (Cramer's V=0.277) and last three months (Cramer's V=0.259), and number of referring to the hospital in the last one year (Cramer's V=0.210). While there was no correlation between the use of these drugs and tendency to engage in violence against others (Cramer's $\mathrm{V}=0.033$ ), there was a positive correlation between the use of these drugs and tendency to engage in violence against the self (Cramer's $V=0.057)$. There was also a positive correlation between the use of these drugs and withdrawal symptoms such as sweating (Cramer's V $=0.068$ ), having fever (Cramer's V=0.095), vomiting (Cramer's V=0.072), hallucination (Cramer's $\mathrm{V}=0.120$ ), headache (Cramer's $\mathrm{V}=0.088$ ), sleeplessness (Cramer's V=0.276), nightmare (Cramer's V=0.133), and epileptic seizure (Cramer's V=0.096).

There was a positive correlation between the multiple drug use and alcohol addiction (Cramer's $\mathrm{V}=0.056$ ), dope addiction (Cramer's V=0.033), number of going to the infirmary in the last one year (Cramer's $\mathrm{V}=0.137$ ), last six months (Cramer's $\mathrm{V}=0.129$ ) and last three months (Cramer's $\mathrm{V}=0.087$ ) and number of referring to the hospital in the last one year (Cramer's $\mathrm{V}=0.124$ ), last six months (Cramer's $\mathrm{V}=0.120$ ), and last three months (Cramer's V=0.070). While there was no correlation between the multiple drug use and tendency to engage in violence against others (Cramer's V=0.76), there was a positive correlation between the multiple drug use and tendency to engage in violence against the self (Cramer's $V=0.075)$. There was a positive correlation between the multiple drug use and withdrawal symptoms such as sweating (Cramer's V=0.068), having fever (Cramer's V=0.086), stomachache (Cramer's V=0.127), nausea (Cramer's $\mathrm{V}=0.147$ ), vomiting (Cramer's $\mathrm{V}=0.151$ ), hallucination (Cramer's V=0.223), headache (Cramer's V=0.087), nervousness (Cramer's V=0.076), sleeplessness (Cramer's V=0.151), nightmare (Cramer's V=0.189), and restlessness (Cramer's V=0.075).

However, there was no significant correlation between the duration of imprisonment ( $<6$ months in $14.7 \%, 6$ months -1 year in $16 \%, 1-3$ years in $30.3 \%, 3-6$ years in $13.9 \%, 6-10$ years in $11.9 \%$ and $>10$ years in $13.2 \%$ ) and other variables.

\section{DISCUSSION}

The major finding of our study is that it is the first study about the use of gabapentinoids and addiction in penal institutions. One of the limitations of our study is that since the participants were completely free in participating in the questionnaire and answering the questions, there was a high dependence on participants, particularly about not telling the truth in terms of drug addiction and abuse. By a higher participation and application of a stricter questionnaire accompanied by medical records, independent of participants, the results would be much realistic. The response rate was low to some questions, as they were concerning the small part of the participants who were using 
gabapentinoids. For instance, the question asking the pregabalin drug report or the question asking the duration of pregabalin use had response rates about $20 \%$, as the participants who did not use pregabalin previously did not answer these questions. However, the response rates in the questions that concern all the participants were high (Table 1).

According to the drug market data, it was estimated that the number of individuals using gabapentin was about 240,682 , while the number of individuals using pregabalin was about 249,793 . Considering that the population above 18 years old was 52,314,553 individuals (according to 2014 data of Turkish Statistical Institute), ${ }^{[20]}$ it was thought that the rate of gabapentinoid usage of normal population was about $0.94 \%$. At the E column in Table 3, it is seen that the rate of gabapentinoid usage was quite above the normal population, particularly in some institutions.

It was found that pregabalin, which is recommended to be used twice a day, was used at a percent of $14.3 \%$ three times a day and more. While ideal daily dose of pregabalin is accepted as $300 \mathrm{mg}$ (rarely can be increased up to $600 \mathrm{mg} /$ day), it was used at a percent of $43.9 \%$ more than $300 \mathrm{mg}$ daily. This may be due to the fact that the drug was abused or that the patients and infirmary personnel were not sufficiently informed by physicians. Moreover, that $59 \%$ started pregabalin after imprisonment and $48.5 \%$ used it for $\geq 6$ months can be interpreted as to be careful in terms of abuse and addiction. It was found that gabapentin, which is recommended to be used as at least $1,800 \mathrm{mg}$ daily in three divided doses, was used in true frequency only by $49.5 \%$ of the participants and in true doses only by $47.8 \%$. Similar to pregabalin, that $54.4 \%$ started gabapentin after imprisonment and $64.7 \%$ used it for $\geq 6$ months can be interpreted as to be careful in terms of abuse and addiction.

The fact that 36 participants (2\%) have used these two groups of drugs simultaneously, although simultaneous use of pregabalin and gabapentin is not recommended, shows the importance of questioning drug use by physicians, sufficiently informing the patient and considering drug abuse. Besides, the rate of high usage of antidepressant, antipsychotic, or other antiepileptic drugs, and mostly starting these drugs after imprisonment and their long duration of use indicate that the physicians should be careful while managing the treatments. That $16.6 \%$ of the participants have used drugs simultaneously in more than one group and $2 \%$ of them have used gabapentinoid + antidepressant + antipsychotic simultaneously revealed the requirement for being careful about multiple drug use and drug abuse and addiction.

Neuropathic pain examples encountered in the clinic can be considered as post herpetic neuralgia, diabetic neuropathy, post-traumatic neuralgia and central post-stroke pain syndrome. Frequently encountered symptoms in neuropathic pain cases are spontaneous pain, allodynia, hyperalgesia, and paresthesia in the painful region. ${ }^{[21]}$ The presence of neuropathic pain in $35.5 \%$ of the participants suggests the question whether the necessary criteria were adequately questioned for this diagnosis, as the maximum prevalence of neuropathic pain is $1 \%$ in the Western societies. ${ }^{[21]}$

The high rate of those reporting that they were alcohol and/or drug addicted strengthen the predictions regarding that probability of addiction may be high in penal institutions, and reveal the possibility that use of gabapentinoids which can also be used in the treatment of addiction can be more than predicted in penal institutions.

The numbers of going to the infirmary and referring to the hospital were generally high in participants. However, the rates of referring to the hospital were lower in the last three months, compared to the last one year. This can be interpreted in a way that condition of the patients becomes more stabilized as a result of the treatment.

Withdrawal symptoms such as restlessness, sleeplessness and nervousness show that abuse and addiction potential of these drugs should be kept in mind. Significant correlations between the gabapentinoid use, dose, usage frequency, duration of use and alcohol/dope addiction, number of going to the infirmary, referring to the hospital and also various withdrawal symptoms suggest abuse and addiction potential of these drugs, and also it should be noted that they may have a role in the treatment of addiction.

There was a significant correlation between the use of other drugs comprising antidepressant, antipsychotics, other antiepileptics, and alcohol/dope addiction, the number of going to the infirmary and referring to the hospital and also various withdrawal symptoms. Also, multiple drug use was high and there was significant correlation between the multiple drug use and alcohol/dope addiction, number of going to the infirmary and referring to the hospital and also various withdrawal symptoms.

The presence of the results which can be accepted as contradictory in the questions about violence against others or violence against the self were attributed to 
the accuracy and consistency levels of the answers given by the participants to these questions.

Addiction is a chronic neurobiological disease involving genetic, psychosocial, and environmental factors in its development. Addiction is a manifestation occurring when a substance is taken for the wrong purposes and in gradually increasing amounts as a result of the tolerance developing against that substance, when it is continued to be used although it causes problems in the life of the person, and as withdrawal symptoms appear, when substance intake is reduced or quitted. The common feature of the addictive substances is that they have a reinforcing effect on their intake. Due to the effects on the reward system in brain, the person is addicted to pleasureinducing feature of the substance and becomes addicted upon using it repeatedly. Addicted person continues to use substance s/he is addicted compulsively despite negative results s/he experienced.

It is shown that the usage rates of antipsychotic and antidepressant were quite high among those participating in our study. The studies conducted with antidepressant drugs have shown that these drugs back up the treatment in the presence of comorbid depression in alcohol addicts, they treat depression and reduce alcohol intake. ${ }^{[22-25]}$ Although typical antipsychotics relieve the psychotic symptoms originating from dope addictions, usage frequency of substance may increase in these patients due to the side effects. Studies on olanzapine, clozapine, and quetiapine in regard to the use of antipsychotics in the treatment of alcohol addiction are available. In previous studies, the results regarding that olanzapine, clozapine treatments decreased the desire for alcohol in patients diagnosed with schizophrenia and schizoaffective disorder. ${ }^{[26-28]}$ The studies examining the effects of quetiapine on alcohol and substance intake were conducted primarily in the patient populations accompanied by bipolar and schizophrenia diagnoses. Quetiapine was associated with the days of staying sober in the alcohol addiction and is shown to have reduced anxiety, depression and food craving. Several studies have shown that it increases substance abuse in patients only with substance use disorders. On the other hand, cases about the abuse of quetiapine and risk of addiction are increasing more and more in the literature. The most promising antipsychotic agent in the treatment of alcohol addiction seems to be aripiprazole. In a study comparing the aripiprazole, a partial dopamine agonist, with naltrexone, it is reported that aripiprazole is as effective as naltrexone in reducing alcohol use and food craving. ${ }^{[29-31]}$ Antiepileptic drugs are known to be used frequently in the treatment of cleaning in alcohol addiction, withdrawal symptoms and epileptic seizures. ${ }^{[32]}$ Data regarding that valproate and lamotrigine reduce the desire for and intake of alcohol in the patients with bipolar disorder are obtained. ${ }^{[32-34]}$ The GABA and gabapentin are among the agents the use of which would be considered in the treatment of alcohol addiction, particularly in the withdrawal period in the future. ${ }^{[22,35]}$

Several studies have concluded that pregabalin does not show apparent drug interactions, and there is not any tolerance and abuse; ${ }^{[36]}$ however Grosshans et al. ${ }^{[17]}$ presented the first pregabalin addiction case in 2010. A 47-year-old male patient in whom pregabalin was started due to alcohol addiction used 7,500 $\mathrm{mg}$ /day pregabalin to eliminate alcohol withdrawal symptoms. Although no toxic finding was encountered, sweating, shivering, restlessness, and hypertension were seen in its deprivation and these findings were treated with benzodiazepines; however, the patient continued to use $6,000 \mathrm{mg} /$ day pregabalin again. It is concluded that it is necessary to pay attention, particularly to those who have an addiction history in regard to the abuse of pregabalin. ${ }^{[17]}$ There was a significant correlation between the pregabalin use and various withdrawal symptoms in our study.

It is found that the usage rate of pregabalin and gabapentin together with antipsychotic/ antidepressants was high in our study. This situation gives rise to the thought that gabapentinoids can be used off-label with neuropathic pain or epilepsy diagnoses, although they have not taken the aforementioned indications yet in Turkey.

In conclusion, although gabapentinoids seem to be used in the treatment of addiction and are proved effective treatment agents in terms of true diagnosis, suitable follow-up and timely completion of the treatment, it is necessary to strictly control their use due to the probability of abuse and addiction.

\section{Declaration of conflicting interests}

The authors declared no conflicts of interest with respect to the authorship and/or publication of this article.

\section{Funding}

The authors received no financial support for the research and/or authorship of this article.

\section{REFERENCES}

1. Dooley DJ, Donovan CM, Meder WP, Whetzel SZ. Preferential action of gabapentin and pregabalin at P/Q-type voltage-sensitive calcium channels: inhibition of K+-evoked $[3 \mathrm{H}]$-norepinephrine release from rat neocortical slices. Synapse 2002;45:171-90. 
2. Gee NS, Brown JP, Dissanayake VU, Offord J, Thurlow R, Woodruff GN. The novel anticonvulsant drug, gabapentin (Neurontin), binds to the alpha2delta subunit of a calcium channel. J Biol Chem 1996;271:5768-76.

3. Kelly KM. Gabapentin. Antiepileptic mechanism of action. Neuropsychobiology 1998;38:139-44.

4. Dooley DJ, Donovan CM, Pugsley TA. Stimulus-dependent modulation of $[(3) \mathrm{H}]$ norepinephrine release from rat neocortical slices by gabapentin and pregabalin. J Pharmacol Exp Ther 2000;295:1086-93.

5. Jones DL, Sorkin LS. Systemic gabapentin and S(+)-3isobutyl-gamma-aminobutyric acid block secondary hyperalgesia. Brain Res 1998;810:93-9.

6. Fink K, Dooley DJ, Meder WP, Suman-Chauhan N, Duffy $\mathrm{S}$, Clusmann $\mathrm{H}$, et al. Inhibition of neuronal $\mathrm{Ca}(2+)$ influx by gabapentin and pregabalin in the human neocortex. Neuropharmacology 2002;42:229-36.

7. Dooley DJ, Mieske CA, Borosky SA. Inhibition of $\mathrm{K}(+)$-evoked glutamate release from rat neocortical and hippocampal slices by gabapentin. Neurosci Lett 2000;280:107-10.

8. Maneuf YP, Hughes J, McKnight AT. Gabapentin inhibits the substance P-facilitated $\mathrm{K}(+)$-evoked release of $[(3) \mathrm{H}]$ glutamate from rat caudial trigeminal nucleus slices. Pain 2001;93:191-6.

9. Bialer M, Johannessen SI, Kupferberg HJ, Levy RH, Loiseau P, Perucca E. Progress report on new antiepileptic drugs: a summary of the fourth Eilat conference (EILAT IV). Epilepsy Res 1999;34:1-41.

10. Welty D, Wang Y, Busch JA, Taylor CP, Vartanian MG, Radulovic LL. Pharmacokinetics (PK) and pharmacodynamics (PD) of CI-1008 (pregabalin) and gabapentin in rats with maximal electroshock. Epilepsia 1997;38:35.

11. Brodie MJ, French JA. Management of epilepsy in adolescents and adults. Lancet 2000;356:323-9.

12. Oulis P, Konstantakopoulos G. Pregabalin in the treatment of alcohol and benzodiazepines dependence. CNS Neurosci Ther 2010;16:45-50.

13. Perrot S, Dickenson AH, Bennett RM. Fibromyalgia: harmonizing science with clinical practice considerations. Pain Pract 2008;8:177-89.

14. Arnold LM, Goldenberg DL, Stanford SB, Lalonde JK, Sandhu HS, Keck PE Jr, et al. Gabapentin in the treatment of fibromyalgia: a randomized, double-blind, placebo-controlled, multicenter trial. Arthritis Rheum 2007;56:1336-44.

15. Schwan S, Sundström A, Stjernberg E, Hallberg E, Hallberg P. A signal for an abuse liability for pregabalin--results from the Swedish spontaneous adverse drug reaction reporting system. Eur J Clin Pharmacol 2010;66:947-53.

16. Ilhanli I, Guder N. Abuse and addiction of gabapentinoids versus treatment: Two sharp knife edges. Int J Curr Pharmaceut Clin Res 2016;6:4-9.

17. Grosshans M, Mutschler J, Hermann D, Klein O, Dressing $\mathrm{H}$, Kiefer $\mathrm{F}$, et al. Pregabalin abuse, dependence, and withdrawal: a case report. Am J Psychiatry 2010;167:869.

18. Yargic I, Özdemiroglu FA. Pregabalin abuse: Case report. Bulletin of Clinical. Psychopharmacology 2011;21:64-6.

19. Teltzrow R. Drug use in Prisons-Risks, Public Health and
Human Rights. International Conference on Mental Health and Addiction; 2013 Feb 27-28; Bucharest; 2013. p. 5-9.

20. Available from: www.tuik.gov.tr

21. Neuropathic pain. Available from: http://www.jcp.sagepub. com/cgi/content/full

22. Patel KH. Pharmacologic management of alcohol dependence. US Pharmacist 2009;. 34:1-4.

23. Graham K, Massak A. Alcohol consumption and the use of antidepressants. CMAJ. 2007;176:633-7.

24. Muhonen LH, Lahti J, Sinclair D, Lönnqvist J, Alho H. Treatment of alcohol dependence in patients with co-morbid major depressive disorder--predictors for the outcomes with memantine and escitalopram medication. Subst Abuse Treat Prev Policy 2008;3:20.

25. García-Portilla MP, Bascarán MT, Saiz PA, Mateos M, González-Quirós M, Pérez P, et al. Effectiveness of venlafaxine in the treatment of alcohol dependence with comorbid depression. Actas Esp Psiquiatr 2005;33:41-5.

26. Hutchison KE, Ray L, Sandman E, Rutter MC, Peters A, Davidson D, et al. The effect of olanzapine on craving and alcohol consumption. Neuropsychopharmacology 2006;31:1310-7.

27. Azorin JM, Bowden CL, Garay RP, Perugi G, Vieta E, Young AH. Possible new ways in the pharmacological treatment of bipolar disorder and comorbid alcoholism. Neuropsychiatr Dis Treat 2010;6:37-46.

28. Wiesbeck GA, Weijers HG, Lesch OM, Glaser T, Toennes PJ, Boening J. Flupenthixol decanoate and relapse prevention in alcoholics: results from a placebo-controlled study. Alcohol Alcohol 2001;36:329-34.

29. Martinotti G, Di Nicola M, Di Giannantonio M, Janiri L. Aripiprazole in the treatment of patients with alcohol dependence: a double-blind, comparison trial vs. naltrexone. J Psychopharmacol 2009;23:123-9.

30. Wang LL, Yang AK, He SM, Liang J, Zhou ZW, Li Y, et al. Identification of molecular targets associated with ethanol toxicity and implications in drug development. Curr Pharm Des 2010;16:1313-55.

31. Erdoğan A, Yurteri N. Aripiprazole treatment in the adolescent patients with inhalants use disorders and conduct disorder: a retrospective case analysis. Symposium 2010; 48:229-33.

32. Fernandez Miranda JJ, Marina González PA, Montes Pérez M, Díaz González T, Gutierrez Cienfuegos E, Antuña Díaz MJ, et al. Topiramate as add-on therapy in non-respondent alcohol dependant patients: a 12 month follow-up study. Actas Esp Psiquiatr 2007;35:236-42.

33. Johnson BA, Rosenthal N, Capece JA, Wiegand F, Mao L, Beyers K, et al. Topiramate for treating alcohol dependence: a randomized controlled trial. JAMA 2007;298:1641-51.

34. Rubio G, López-Muñoz F, Alamo C. Effects of lamotrigine in patients with bipolar disorder and alcohol dependence. Bipolar Disord 2006;8:289-93.

35. Kampman KM. New medications for the treatment of cocaine dependence. Ann Ist Super Sanita 2009;45:10915 .

36. Bech P. Dose-response relationship of pregabalin in patients with generalized anxiety disorder. A pooled analysis of four placebo-controlled trials. Pharmacopsychiatry 2007;40:163-8. 